\title{
Ciberpolítica, ciberativismo e cibercultura: uma análise dos papers apresentados no grupo de trabalho da Anpocs ${ }^{1}$
}

\author{
Rafael Cardoso Sampaio ${ }^{2}$ \\ Isabele Mitozo ${ }^{3}$ \\ Michele Goulart Massuchin ${ }^{4}$ \\ Giulia Sbaraini Fontes 5 \\ Cláudio Luis de Camargo Penteado ${ }^{6}$
}

\section{Introdução}

A internet nasce do improvável encontro entre o projeto militar de comunicação (Arpanet), a inserção da big science no desenvolvimento de tecnologias de informação e a cultura libertária californiana (CASTELLS, 2003). Segundo o sociólogo catalão, a junção desses três movimentos com perfis diferenciados criou condiçóes econômicas, tecnológicas e culturais para a formação de uma nova estrutura comunicacional, com o uso de microprocessadores e estruturada na forma de rede distribuída, que vem provocando profundas transformaçóes sociais, econômicas, políticas e culturais. Por sua vez, a internet comercial surge em meados dos anos 1980 , enquanto a world wide web é de meados dos anos 1990 e rapidamente se torna a tecnologia de comunicação e informação (TIC) com a mais rápida expansão da história humana ${ }^{7}$.
Mesmo que ainda exista uma grande parcela da população mundial sem acesso à internet, os efeitos e as transformaçóes do uso dessa tecnologia já se impóem diretamente para quase toda a população mundial, mesmo que de forma indireta. A arquitetura distribuída, o desenvolvimento de processos colaborativos e a interatividade entre os usuários possibilitam a emergência de novas relaçóes, tecidas de forma horizontal nesse meio. Emerge um novo modelo de reestruturação da produção, organizado em rede e de acordo com o uso crescente das TICs, em que a informação assume o papel de matéria-prima na constituição da Sociedade em Rede (Idem, 1999).

Nesse contexto, boa parte das questóes iniciais sobre essa aproximação, do ponto de vista político, se deram na perspectiva de responder o que a internet pode fazer pela democracia, recebendo tanto respostas bastante céticas quanto entusiasmadas sobre os potenciais dos então

1 Uma versão prévia deste artigo foi apresentada no Grupo de Trabalho Ciberpolítica, Cibercultura e Ciberativismo, durante o 41 Encontro Anual da Anpocs, em Caxambu, entre os dias 23 e 27 de outubro de 2017. Os autores e as autoras agradecem as sugestóes dos participantes do GT. Parte da pesquisa foi realizada com apoio do Laboratório de Análise do Campo Científico da Universidade Federal do Paraná (LaCC-UFPR).

2 Professor do curso de Ciências Sociais na Universidade Federal do Paraná (UFPR). E-mail: cardososampaio@gmail.com

3 Pesquisadora em estágio pós-doutoral no Instituto Nacional de Ciência e Tecnologia em Democracia Digital (INCT. DD/Brasil). Doutora em Ciência Política pela Universidade Federal do Paraná (UFPR). E-mail: ibmitozo@gmail.com

4 Professora do curso de Jornalismo da Universidade Federal do Maranhão (Ufma). E-mail: mimassuchin@gmail.com

5 Doutoranda em Ciência Política na Universidade Federal do Paraná (UFPR). Mestre em Ciência Política pela mesma instituição. E-mail: giuliasfontes@gmail.com

6 Professor Associado da Universidade Federal do ABC (UFABC). E-mail: claudio.penteado@ufabc.edu.br

7 Em 2001, 8\% da população mundial tinha acesso à rede mundial de computadores; já são 45,9\% da população em 2016, segundo dados do Telecommunication Development Sector (ITU-D). No Brasil, o número de usuários já passa da metade da população, atingindo 58\% dos cidadãos e representando 102 milhóes de internautas (CGI. br, 2018). 
novos meios de comunicação e informação. $\mathrm{O}$ efeito das tecnologias eletrônicas e digitais sobre as atividades políticas, sociais e culturais se configura como preocupação relativamente antiga nas ciências humanas e sociais.

Conforme estudo realizado por Gomes (2016), a atenção acadêmica para as relaçóes entre os meios digitais e as práticas políticas já é consolidada, havendo mais de 4 mil estudos em quase 25 anos de existência das TICs, com o estabelecimento de ao menos três grandes áreas de estudo: e-política, democracia digital e Estado digital, com as práticas sociais ganhando proeminência no primeiro eixo.

Em relação ao Brasil, o estudo de Sampaio, Bragatto e Nicolás (2016) analisa 526 artigos publicados nos registros dos principais eventos acadêmicos de comunicação e de ciências sociais no país, no período de 2000 a 2014, demonstrando que aquelas subáreas estão também consolidadas na pesquisa nacional. Por outro lado, há uma concentração de artigos apresentados em eventos de comunicação e por pesquisadores/as dessa área (45,6\%), enquanto pesquisadores/as dos programas de pós-graduação das áreas de ciências sociais em conjunto (ciências sociais, ciência política e sociologia) representam 29,4\% da produção analisada. Dessa maneira, considerando a consolidação do grupo de trabalho (GT) Ciberpolítica, Ciberativismo e Cibercultura na Associação Nacional de Pós-Graduação e Pesquisa em Ciências Sociais (Anpocs), criado em 2010 e mantido de forma ininterrupta até então, é nosso objetivo investigar exclusivamente os trabalhos apresentados nesse espaço, compreendendo-o como uma pequena amostra do interesse acadêmico pelo tema e da relevância deste para as ciências sociais.

Desse modo, o artigo se divide em cinco seçóes. A primeira delas apresenta um panorama da consolidação das pesquisas em cibercultura e ciberpolítica no país, dando destaque para a criação de grupos de trabalho em eventos acadêmicos de comunicação e de ciências sociais e para a consolidação do campo de pesquisa. Mais adiante, apresentam-se os procedimentos metodológicos adotados. A terceira seção consiste na análise dos dados obtidos, que é seguida da discussão dos resultados. Por fim, apresentam-se algumas consideraçóes sobre a investigação, abrindo espaços para pesquisas mais abrangentes sobre a incidência dos trabalhos acerca da temática em tela em outros eventos nacionais.

\section{Internet, política e cibercultura: a consolidação de uma nova área de pesquisas}

A área de pesquisa em ciberpolítica, ciberativismo e cibercultura se caracteriza pela interdisciplinaridade e pelas constantes inovaçóes tecnológicas, que se refletem na dinâmica do objeto e dos métodos de pesquisa. Situada em zonas de fronteira entre a comunicação e as ciências sociais, com aportes e diálogos com outras áreas do conhecimento (administração, ciência da informação, ciência da computação, direito, filosofia, psicologia, etc.), cria-se uma área aberta para contribuiçóes de saberes provenientes de diferentes áreas. As rápidas transformaçóes das TICs levam ao surgimento de novas agendas que visam estudar as mudanças inseridas pelas inovaçôes tecnológicas, desafiando pesquisadores e pesquisadoras com novos problemas, assim como trazendo novas técnicas para a investigação científica.

Os primeiros estudos acadêmicos voltados para a área ocorrem no campo da cibercultura, no qual pesquisadores/as, geralmente de comunicação, começam a estudar a emergência de novas práticas culturais que se estabelecem pelo uso e pela interação com as Tecnologias de Informação e Comunicação (TICs). Segundo Amaral e Montardo (2012), o termo cibercultura é popularizado entre a metade dos anos 1980 e início dos anos 1990, e chega ao Brasil em torno de 1996 por meio dos 
textos de André Lemos e Eugênio Trivinho. A título de exemplo, a tradução do influente livro Cibercultura, de Pierre Lévy, seria lançada em 1999 no Brasil, enquanto André Lemos lançaria o livro Cibercultura: tecnologia e vida social na cultura contemporânea em 2002, marcando em definitivo tal área de estudos no país.

Segundo Lévy (1999, p. 17), "cibercultura especifica o conjunto de técnicas (materiais e intelectuais), de práticas, de atitudes, de modos de pensamento e de valores que se desenvolvem juntamente com o crescimento do ciberespaço". Ou seja, análises e reflexóes acerca dos impactos das tecnologias digitais e móveis em "hábitos sociais, práticas de consumo cultural, ritmos de produção e distribuiçâao da informação, [criam] novas formas de sociabilidade de comunicação social" (LEMOS; LÉVY, 2010, p. 22).

Para Lemos e Lévy (Ibid.), a cibercultura estaria assentada em três princípios fundamentais. O tripé seria composto de: (a) liberaçẫo do polo de emissão ou da palavra, ou seja, as múltiplas possibilidades geradas pelos meios digitais para as pessoas passarem a emitir suas próprias informaçôes ao invés de apenas serem expectadoras das mídias massivas, o que impactaria na emergência de novas formas de comunicação e de veiculação da opiniấo pública; (b) princípio da inteligência coletiva, segundo o qual a interconexão planetária aliada à liberação da emissão permitiria o estabelecimento de sinergia entre competências, recursos e projetos que envolvessem a ativação de modos de cooperação flexíveis e transversais, permitindo a criação de um conhecimento coletivo cujo alcance náo seria possível individualmente; $\mathrm{e}$ (c) reconfiguraçáo social, cultural e política, que é impactada pelos dois princípios anteriores e baseada em funções pós-massivas da comunicação. $\mathrm{O}$ "sistema pós-massivo permite a personalização, o debate náo mediado, a conversação livre, a desterritorialização planetária” (Ibid., p. 26).

$\mathrm{Na}$ área de comunicação, a cibercultura seria institucionalizada com a criação de grupos de trabalho específicos nos principais eventos da área, nomeadamente promovidos pela Associação Brasileira de Estudos Interdisciplinares da Comunicação (Intercom) e pela Associação Nacional dos Programas de Pós-Graduação em Comunicação (Compós), e com a criaçáo de linhas de pesquisa em programas de pós-graduação, como foi o caso do PPGCOM da Universidade Federal da Bahia. Houve, ainda, a publicação da coletânea Cibercultura pela editora Sulina, que passou a editar compilaçóes e livros autorais sobre o tema, incluindo as duas obras citadas anteriormente (AMARAL; MONTARDO, 2012). A institucionalização culminaria na criação, em 2006, da Associação Brasileira de Pesquisadores em Cibercultura (ABCiber), que passou a realizar eventos anualmente com uma série de temáticas dentro do assunto, diversas delas próximas aos objetos da interface "internet e política". Até 2017, dez encontros anuais haviam sido realizados.

Como uma área de estudos bastante abrangente, a cibercultura realizou parte das primeiras reflexóes acerca dos impactos dos novos meios de comunicaçáo e informação sobre cultura, sociabilidade e política, desenvolvendo pesquisas ligadas às inovaçóes tecnológicas e suas apropriaçôes por cidadãos usuários. Foram estabelecidas, assim, intersecçôes não apenas com outras áreas da comunicação, como o jornalismo (i.e., ciberjornalismo), mas também com as ciências sociais, como as reflexóes acerca do impacto do digital sobre formas de ação coletiva (i.e., ciberativismo) ou mesmo sobre técnicas de pesquisa antropológica (p.ex., netnografia).

Paralelamente a isso, podemos falar da subárea "internet e política" ou ciberpolítica. Diferentemente do campo da cibercultura, ela surgiria como um subcampo de estudos de comunicação e política e, consequentemente, como uma área interdisciplinar entre a comunicação social e a ciência política. Segundo 
Miguel e Biroli (2010), o interesse nas relaçôes entre mídia e política estaria centrado em quatro pontos: (1) a mídia se tornou o principal instrumento de contato entre a elite política e os cidadáos comuns; (2) a mídia é a principal responsável pela produção da agenda pública, o que levou (3) o discurso político a se transformar, adaptando-se às formas preferidas pelos meios de comunicaçáo de massa; $\mathrm{e}$ (4) candidatos a posiçóes de destaque político têm de adotar uma preocupação central com a gestão de suas visibilidades e imagens públicas. A esse respeito também são elucidativos os estudos de Gomes (2004) e Weber (2009).

Essa mudança apontava certa substituição dos partidos políticos pelos meios de comunicação de massa como intermediadores entre cidadãos e políticos em situaçôes como: (a) definir a agenda dos temas relevantes para a discussão na esfera pública; (b) gerar e transmitir informaçôes políticas; (c) fiscalizar a ação das administraçôes públicas; (d) exercer a crítica das políticas públicas; (e) canalizar as demandas da população ao governo (LIMA, 2009).

Como indicado por Rubim e Azevedo, os estudos sobre comunicação e política já existem desde as décadas de 1970 e 1980 no Brasil (ainda sob a alcunha "comunicação e poder"), "articulados pela preocupação dominante de pensar as mídias como aparelhos de luta política e principalmente ideológica" (RUBIM; AZEVEDO, 1998, p. 190). A área, entretanto, ganha verdadeiramente força após o processo de redemocratização com as eleiçóes presidenciais de 1989.

Alguns outros fatores são importantes para compreender a consolidação da pesquisa acerca da comunicação e política. Como ressaltado por Lima, "as características históricas específicas do sistema de mídia no Brasil potencializam o seu poder no processo político" (LIMA, 2009, p. 28). A falta de regularização no setor, por exemplo, permitiu oligopólios, propriedades cruzadas e forte alinhamento de famílias e setores midiáticos com governantes no período da ditadura militar, como foi o caso das Organizaçôes Globo. Isso é reforçado pelas "características específicas da população brasileira [que] historicamente potencializaram o poder da mídia no processo político, sobretudo, no processo eleitoral" (Ibid., p. 29), como o alto analfabetismo, a baixa escolarização e o baixo interesse político. Finalmente, a implantação do inovador modelo do Horário Gratuito de Propaganda Eleitoral (HGPE) pode ser considerado um último marco desse momento inicial. Sendo de exibição obrigatória nos sistemas de rádio e TV, o HGPE é um espaço exclusivo aos agentes políticos e a suas campanhas, com significativos efeitos sobre elas e as intençóes de voto (a ponto de influenciar a união de coligaçôes pelo "tempo de TV"). Esse recurso se tornaria rapidamente um dos objetos mais estudados pela área de comunicação e política (ALBUQUERQUE, 2010; DIAS, 2013; FIGUEIREDO et al., 1997; PANKE; CERVI, 2011). Segundo Figueiredo et al. (1997), a eminência do HGPE nas campanhas eleitorais teria sido um importante marco para o crescente interesse da ciência política na temática.

Conforme a pesquisa de Sampaio, Bragatto e Nicolás (2016, p. 288), os estudos sobre "internet e política" ou ciberpolítica começam a surgir logo após os anos 2000, fazendo reflexóes mais gerais acerca da regulação do novo meio e do impacto da internet sobre instâncias políticas tradicionais, como "engajamento cívico, formação da vontade política, criação ou reforço da coesão social entre grupos de interesse, participação política, capital social, cultura política, relação entre a classe dos representantes e dos representados, campanhas políticas". Segundo os autores, apesar de ser uma subárea (ou seja, nascida dentro de interesses mais ampliados de comunicação e política), a ciberpolítica teria características próprias e diferentes da área 
maior, notadamente associada às especificidades tecnológicas.

Enquanto as relaçóes sobre mídia e política são constantemente avaliadas sob um viés negativo, que denota o esvaziamento do discurso político para se adaptar à gramática midiática e à geração de uma espiral do cinismo fomentada pela cobertura constantemente negativa das açóes políticas pelo jornalismo (GOMES, 2004), a ciberpolítica teria originalmente uma visão mais otimista sobre o potencial dos (então) novos meios para a mitigaçáo de déficits democráticos. Isso pode ser constatado pela análise de Sampaio et al. (2016), que denota a importância de temas da democracia digital (participação, deliberação e engajamento) sobre temas da política digital, como estratégia política e campanhas eleitorais. Para Gomes (2016), na verdade todos os estudos sobre internet e política são em maior ou menor medida gestados originalmente sob o guarda-chuva intelectual da democracia digital. Em um primeiro momento, era necessária a justificativa de recursos e esforço acadêmico para os novos meios, o que foi alcançado com a legitimidade trazida por estudos sobre gestar melhorias para a democracia. Náo obstante, as pesquisas mais empíricas e mais orientadas a outras questôes, que não as democráticas, passam gradativamente a ganhar força e espaço, seja no caso internacional (GOMES, 2016), seja no brasileiro (SAMPAIO et al., 2016).

Cabe destacar também os estudos sobre ativismo online, webativismo ou ciberativismo. As pesquisas dessa subárea nascem das iniciativas pioneiras do uso das TICs pelo Movimento Zapatista no México e dos movimentos antiglobalização do final do século XX. Outros campos de investigação estão voltados para (a) açôes de hacktivismo em favor da emancipação social pelo acesso às informaçôes (SILVEIRA, 2010), (b) uso de dispositivos da internet pelas organizaçóes da sociedade civil na influência de políticas públicas (ARAÚJO et al., 2015) e (c) para as mobilizaçóes políticas pelo uso de mídias sociais para expressão de indignação e esperança - que tiveram início com o ciclo de protestos conhecidos como Primavera Árabe e se espalharam por diversas regióes do planeta, chegando ao Brasil em junho de 2013 (CASTELLS, 2017). Com o avanço das TICs, diversos grupos e organizaçóes ativistas incorporaram o uso dos dispositivos de comunicaçáo da internet em suas práticas de mobilização e divulgação de informaçóes, de forma que hoje já não existe mais distinção entre ativismo online e offline (HARLOW; HARP, 2012).

Em termos acadêmicos, no Brasil, é preciso apontar o papel pioneiro do GT Comunicação e Política, já presente na criação dos GTs da Compós em 1992, por iniciativa de pesquisadores diversos da interface, como Antonio Albino Canelas Rubim, Maria Céres Pimenta, Maria Helena Weber, Murilo Ramos, Sergio Porto, Wilson Gomes, entre outros. Posteriormente, a primeira institucionalização por parte da ciência política ocorre em 1997, com a criação do GT Mídia, Opinião Pública e Eleiçôes na Anpocs, por intermédio dos professores Marcus Figueiredo, à época vinculado ao Instituto Universitário de Pesquisas do Rio de Janeiro (Iuperj), e Vera Chaia, da Pontifícia Universidade Católica de São Paulo (PUC-SP).

Por sua vez, a criação da Associação dos Pesquisadores em Comunicação e Política (Compolítica), em 2006, é um marco na consolidação da área interdisciplinar entre comunicação e ciência política, já que cria o primeiro evento exclusivamente voltado às diferentes temáticas do campo. Em especial, a Compolítica apresenta o primeiro GT stricto sensu a levar a alcunha Internet e Política, coordenado pelo professor Wilson Gomes. No caso da ciência política, a linha interdisciplinar com a comunicaçáo consolidava sua presença com a criação da área temática Comunicação Política e Opinião Pública no congresso da Associação Brasileira de Ciência 
Política (ABCP) em 2008, coordenada por Alessandra Aldé, da Universidade do Estado do Rio de Janeiro (Uerj) e Marcus Figueiredo (Iuperj), o que se mantém até os dias atuais.

$A$ rápida difusão das TICs na sociedade e seu uso massivo por diversos atores e segmentos sociais gerou uma demanda específica de estudos acerca dos impactos e dos efeitos das tecnologias digitais na sociedade, na cultura e no sistema político formal e informal. A emergência desse campo de estudos envolve questôes e abordagens de diferentes áreas do conhecimento. Composto de uma agenda de pesquisa dinâmica e interdisciplinar, a cada dia atrai mais pesquisadores (de diferentes áreas do saber) interessados em estudar os efeitos e as transformaçôes sociais, culturais, tecnológicas e políticas decorrentes das TICs.

Advindo de maneira mais direta da discussão sobre comunicação e política, no geral, e da internet e política, em específico, mas com uma preocupaçáo especial em ofertar um novo espaço para outras discussóes possíveis a respeito do tema, é criado em 2010 o GT Ciberpolítica, Ciberativismo e Cibercultura, coordenado pelos professores Sérgio Amadeu da Silveira, da Universidade Federal do ABC (UFABC) e Sérgio Braga, da Universidade Federal do Paraná (UFPR). O grupo se mantém regularmente ativo até a apresentação deste artigo. A consolidação do GT permite identificar a existência de um campo de estudos específico com foco em internet nas ciências sociais contemporâneas, com objetos, temáticas e métodos próprios, que interage com outras áreas do conhecimento, criando uma diversidade de pesquisas e reflexóes sobre a influência e o impacto das TICs na sociedade contemporânea, assim como o estudo de novas práticas que se estabelecem pelo uso crescente das tecnologias digitais.

A seção seguinte procura apresentar de modo detalhado os procedimentos adotados pela investigação, que possui caráter exploratório, não partindo, portanto, de hipóteses acerca dos dados obtidos - sobretudo porque o corpus é composto por textos de apenas um GT que acolhe a área, dentre tantos outros GTs que compóem eventos nacionais atualmente.

\section{Procedimentos metodológicos}

A primeira etapa desta pesquisa consistiu na coleta dos textos que formariam o corpus do paper. Esse processo foi realizado a partir do website da associaçáo que promove o evento (www.anpocs.com), em que estão armazenados os trabalhos de todas as ediçóes do encontro anual da Anpocs. A partir dessa consulta foram reunidos 106 papers apresentados no GT Ciberpolítica, Ciberativismo e Cibercultura entre 2010, ano em que o GT foi criado, e 2017. Consideraram-se tanto apresentaçóes orais quanto painéis, já que não há essa distinção no site da associação. $\mathrm{Na}$ Tabela 1 apresentamos a distribuição dos trabalhos nos anos contemplados pela pesquisa. As variaçóes no número de artigos disponibilizados ocorrem porque, mesmo que exista uma margem fixa de textos aceitos pelo GT (em torno de doze apresentaçóes orais e cinco painéis), nem todos/as autores/as disponibilizam a versão completa após o evento.

\section{Tabela 1}

Distribuição dos artigos por ano

\begin{tabular}{ccc}
\hline & Frequência & $\%$ \\
\hline 2010 & 15 & 14,2 \\
\hline 2011 & 14 & 13,2 \\
\hline 2012 & 16 & 17 \\
\hline 2013 & 10 & 9,4 \\
\hline 2014 & 13 & 12,3 \\
\hline 2015 & 10 & 9,4 \\
\hline 2016 & 14 & 13,2 \\
\hline 2017 & 14 & 13,2 \\
\hline Total & 106 & 100,0 \\
\hline
\end{tabular}

Fonte: Elaboração própria 
Após a coleta do corpus foi realizada uma análise de conteúdo quantitativa. O livro de códigos construído para a pesquisa toma por base o artigo de Sampaio, Bragatto e Nicolás (2016), adaptando algumas categorias das variáveis de acordo com nosso objeto de estudo ${ }^{8}$. As dezessete variáveis analisadas (Quadro 1) dividem-se em dois grupos: aquelas que se referem a autores/as, e outras que dizem respeito à pesquisa apresentada.

Quadro 1

Variáveis analíticas

\begin{tabular}{|c|c|}
\hline \multirow{7}{*}{$\begin{array}{c}\text { Características } \\
\text { dos/as autores/as }\end{array}$} & Quantidade \\
\hline & Sexo \\
\hline & Instituição \\
\hline & Escolaridade \\
\hline & Área da escolaridade \\
\hline & Parceria institucional \\
\hline & Parceria interdisciplinar \\
\hline \multirow{10}{*}{$\begin{array}{l}\text { Características } \\
\text { dos trabalhos }\end{array}$} & Área temática do artigo \\
\hline & Vertente \\
\hline & Objeto político/social \\
\hline & Objeto tecnológico \\
\hline & Abordagem teórica \\
\hline & Tipo de estudo \\
\hline & Tipo de método \\
\hline & Tipo de técnica \\
\hline & Aplicou estatística? \\
\hline & Qual tipo de estatística? \\
\hline
\end{tabular}

Fonte: Elaboração própria
No primeiro grupo de variáveis, que se referem às características dos autores/as, foram levantadas informaçôes como sexo, instituição à qual pertencem, grau de escolaridade e área em que atuam. Além disso, nos casos em que havia mais de um/a autor/a, observou-se se pertenciam a diferentes instituiçóes de ensino (parceria institucional) e/ou a distintas áreas de pesquisa (parceria interdisciplinar).

Após esse primeiro levantamento, os codificadores passaram à análise do conteúdo dos textos. Inicialmente os trabalhos foram classificados de acordo com a área temática a que pertenciam: ciberpolítica, ciberativismo ou cibercultura. Os papers foram considerados (1) de vertente social, quando diziam respeito ao engajamento cívico, por exemplo; ou (2) de vertente institucional, quando se relacionavam a iniciativas de interaçáo entre Estado e cidadãos? .

Depois dessa primeira classificação ampla, observou-se qual era o objeto político ou social explorado no artigo. Além disso, os trabalhos foram classificados de acordo com o objeto tecnológico que exploravam. Outro aspecto verificado na análise diz respeito à abordagem teórica predominante nos textos.

$\mathrm{Na}$ variável "tipo de estudo", os papers foram classificados como teóricos ou empíricos. Em seguida, ao considerar o método utilizado na pesquisa, os trabalhos poderiam ser quantitativos, qualitativos, bibliográficos ou quantitativos e qualitativos simultaneamente. Estudos teóricos, nesse caso, foram sempre classificados

8 Em caso de interesse em replicar e/ou ampliar o estudo, entrar em contato com os autores por e-mail para a disponibilizaçấo do livro de códigos ou mesmo do banco de dados.

9 Conforme a pesquisa de Sampaio et al. (2016, p. 295), na vertente social "estariam as implicaçóes do meio no engajamento cívico, na esfera pública, na deliberaçáo política e na sua relação com o capital social. Em comum, a preocupação com a formação e as aptidōes políticas da cidadania no ciberespaço”. Segundo Gomes (2007, p. 11), a vertente institucional teria três endereços: "a) a conformação digital das instituiçốes da democracia em sentido estrito (cidades e governos digitais, parlamentos on-line) ou lato (partidos políticos on-line); b) as iniciativas institucionais no vetor que vai do Estado aos cidadãos (como a prestação de serviços públicos on-line e governo eletrônico); c) iniciativas institucionais no vetor cidadãos-Estado (oportunidades de participação ou de oferta de inputs por parte da cidadania na forma de votos, respostas a sondagens, decisóes ou sugestóes orçamentárias, registro e discussão de opinióes em fóruns eletrônicos etc.)". 
como bibliográficos. Somente para estudos empíricos, por fim, foram analisadas outras três variáveis. No caso de estudos empíricos, foi verificada a técnica de pesquisa aplicada e se houve o uso de técnicas estatísticas.

Esse livro de códigos foi aplicado aos 106 trabalhos do corpus por três codificadores/as, após um treinamento para que houvesse concordância entre eles/as. A partir disso, a fim de apreender outras características dos artigos analisados, a pesquisa lança mão de técnicas estatísticas para auxiliar na análise e no cruzamento dos dados, como o uso de frequências simples, cálculo de qui-quadrado e análise de resíduos padronizados. Os resultados são, então, apresentados no tópico a seguir.

\section{Análise dos dados sobre o GT Ciberpolítica, Ciberativismo e Cibercultura}

\section{Características dos/as autores/as}

A partir da análise dos textos que constituem o corpus empírico $(\mathrm{n}=106)$, é possível chegar a alguns achados importantes sobre o modo como o referido GT se estruturou ao longo dos anos, mapeando e inserindo vertentes de pesquisa e instituiçóes. Pode-se primeiramente depreender que, mesmo que a maior parcela dos papers se concentre na parceria entre dois ou mais autores/as (somando $58,5 \%$ ), há predomínio da categoria "autoria individual" nos trabalhos apresentados no GT, conforme pode ser visto na Tabela 2. Dentre eles, 41,5\% são de apenas um/a autor/a. Além disso, é possível dizer que essa constatação inicial já diminui de forma significativa a possibilidade de pesquisas interinstitucionais, o que vai ser analisado adiante.

Outra variável analisada é o sexo dos/as autores/as. Nesse caso são agregados os dados dos/as três primeiros/as autores/as, que foram computados na codificação. O objetivo é identificar se há pluralidade no GT. Percebe-se que, embora haja equilíbrio na autoria principal, com 53 mulheres como primeiras autoras e 53 homens na mesma categoria, no total ainda há mais homens participando do GT em todas as outras posiçóes de autoria observadas. Normalmente, quando há inclusão de mais de um/a autor/a, a tendência é serem homens e não mulheres, o que acaba desequilibrando

Tabela 2

Número de autores por paper apresentado

\begin{tabular}{ccc}
\hline & Frequência & Percentual \\
\hline 1 & 44 & 41,5 \\
\hline 2 & 27 & 25,5 \\
\hline 3 & 31 & 29,2 \\
\hline 4 & 4 & 3,8 \\
\hline Total & 106 & 100,0 \\
\hline
\end{tabular}

Fonte: Elaboração própria

Tabela 3

Sexo dos autores e autoras dos trabalhos

\begin{tabular}{cccccc}
\hline Sexo & $\mathbf{1}^{\mathbf{0}}$ & $\mathbf{2}^{\mathbf{0}}$ & $\mathbf{3}^{\mathbf{0}}$ & Total & \% Total \\
\hline Mulher & 53 & 24 & 13 & 90 & 44,3 \\
\hline Homem & 53 & 38 & 22 & 113 & 55,7 \\
\hline Total & 106 & 62 & 35 & $203^{*}$ & 100 \\
\hline
\end{tabular}

* Temos os dados de 203 e náo de 207 autores/as, pois apenas quatro dos 106 trabalhos possuem quatro autores/as, e na pesquisa fez-se a coleta dos dados referentes aos três primeiros, uma vez que aquele total foi mínimo. Ressalta-se que em 2017 houve uma restrição de cadastro para os alunos de graduação.

Fonte: Elaboração própria

o total. O conjunto dos presentes no GT ao longo dos anos foi composto de 44,3\% de mulheres e 55,7\% de homens.

É importante saber, ainda, se há rotatividade desses/as pesquisadores/as durante os oito 
anos do GT, e se há aqueles/as que se repetem com frequência, ou seja, que participaram várias vezes do evento. $\mathrm{O}$ primeiro dado indica que, entre os/as 203 autores/as, há certa repetição ao longo do tempo. Logo, no total há 130 autores/as únicos/as. A Tabela 4 permite identificar a rotatividade do GT.

Os dados indicam que 96 autores/as (73,8\% do total) participaram do evento apenas uma vez ao longo dos oito anos. Dezoito participaram de duas ediçóes, o que equivale a 13,8\%. Logo, pode-se perceber que em cada edição do evento não há tendência à repetiçáo de autores/as. Do total de 130 autores/as, dezesseis participaram de três ediçóes ou mais.

É importante notar que, dentre os/as cinco autores/as que mais se repetiram ao longo do GT (entre seis e oito ediçóes), há apenas uma mulher. Ainda discutindo gênero, verifica-se que os homens são quase sempre maioria nas sessôes, como ilustra o Gráfico 1, quando se observa a distribuição longitudinal.

Apenas em 2016 e 2017 houve maior presença de mulheres (57\% e 55\%, respectivamente) no referido GT. As maiores diferenças estão em 2011 e 2015, com mais de 65\% de participantes homens. Dessa forma, não há um crescimento contínuo da paridade, que ocorre de modo mais próximo em 2013, 2014 e 2017. Assim, apesar da repentina visibilidade das mulheres em 2016, elas são, no total, minoria.

Outra variável observada pela pesquisa é a universidade representada pelos/as autores/as. Os dados também são agregados e se referem aos/às três autores/as do paper apresentado. Conforme os dados do Gráfico 2 , há uma concentração da representação de

Tabela 4

Rotatividade de autores/as no GT

\begin{tabular}{ccc}
\hline Repetiçáo & Quantidade & Percentual \\
\hline 1 & 96 & 73,8 \\
\hline 2 & 18 & 13,8 \\
\hline 3 & 9 & 6,9 \\
\hline 4 & 2 & 1,5 \\
\hline 5 & 0 & 0,0 \\
\hline 6 & 1 & 0,8 \\
\hline 7 & 2 & 1,5 \\
\hline 8 & 2 & 1,5 \\
\hline Total & 130 & 100,0 \\
\hline
\end{tabular}

Fonte: Elaboração própria

\section{Gráfico 1}

Distribuição de homens e mulheres ao longo dos anos no GT

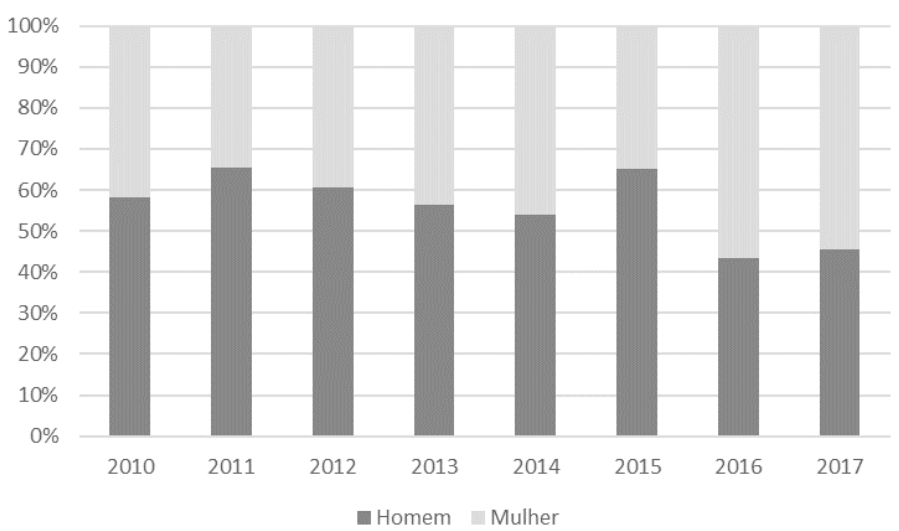

Fonte: Elaboração própria 


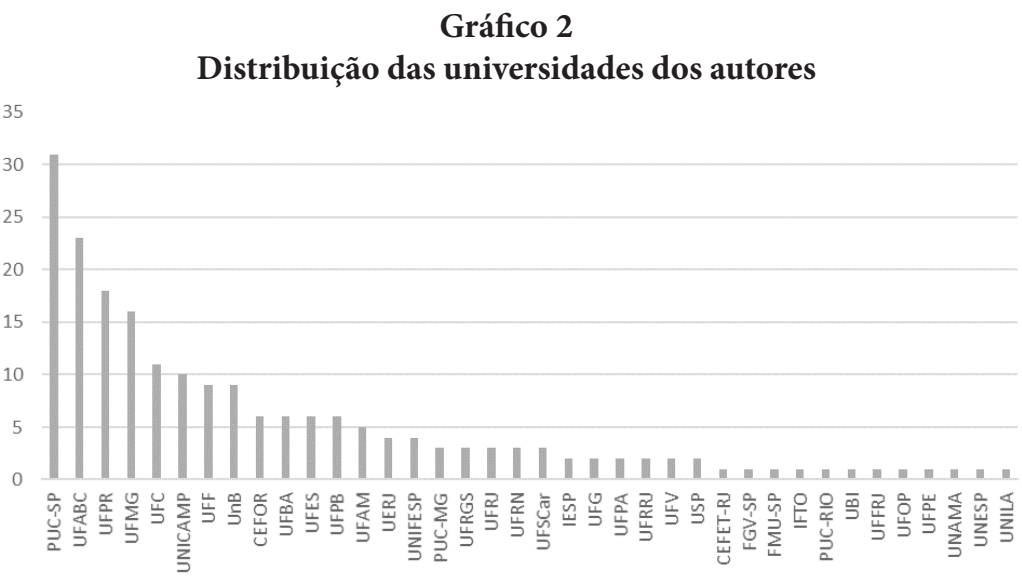

Fonte: Elaboração própria

quatro universidades, que aparecem em quase todos os anos e são centros de referência em estudos da área.

A PUC-SP, a UFABC, a UFPR e a Universidade Federal de Minas Gerais (UFMG) reúnem $42 \%$ de todos os/as autores/as que já participaram do GT. Houve, ademais, um único autor de instituição estrangeira, da Universidade da Beira Interior (UBI, Portugal). A região Norte aparece representada por Universidade Federal do Amazonas (Ufam), Universidade da Amazônia (Unama), Universidade Federal do Pará (Ufpa) e Instituto Federal do Tocantins (IFTO), com cinco autores/as da Ufam e uma autora para cada uma das demais instituiçóes durante o período. O Nordeste aparece representado pelas universidades federais da Bahia (Ufba), da Paraíba (UFPB), do Rio Grande do Norte (UFRN), de Pernambuco (UFPE) e do Ceará (UFC), mas em pouca quantidade em relação ao predomínio das universidades que lideram. Chama a atenção a pouca presença de trabalhos da Ufba, que atualmente é a instituição sede do Instituto Nacional de Ciência e Tecnologia sobre Democracia Digital (INCT.DD) ${ }^{10}$ e do Laboratório de Pesquisa em Mídia Digital, Redes e Espaço (Lab 404) ${ }^{11}$, cujas pesquisas entrariam no escopo do GT em tela.

Destaca-se que as universidades mais representadas (PUC-SP, UFABC, UFPR e UFMG) estão nas regióes Sul e Sudeste, apenas. Das 38 que apareceram (excluída aquela do exterior), 22 são da região Sudeste. Ademais, há três do Sul, quatro do Norte, três do Centro-Oeste e cinco do Nordeste.

Além da observação das instituiçôes, há dados sobre a escolaridade dos autores/as. Da mesma forma, estão agregados os números relacionados aos/às três autores/as $(203 \text { casos })^{12}$.

Percebe-se, a partir da leitura da última coluna do Gráfico 3, que grande parte dos/as primeiros/as autores/as de papers é composta de doutores/as (54\%), seguidos/as de longe por doutorandos/as (21\%). A baixa incidência de

10 Disponível em: <https://www.facebook.com/inct.dd/>. Acesso em: 25 set. 2017.

11 Dedicado a estudos sobre cibercultura. Disponível em: <www.lab404.ufba.br/>. Acesso em: 25 set. 2017.

12 Consideramos a autoria de todos os papers, logo, contabilizam-se as autorias de cada estudo, não os autores em si, como outrora neste trabalho. Assim, no total são 130 "autores únicos". 
mestres/as pode apontar para o fato de que o evento é almejado por quem está ativamente no meio acadêmico, seja como docente ou discente de programas de pós-graduação. Com relação aos/às mestrandos/as (14\%), a frequência mais próxima àquela de doutorandos/as pode indicar maior ocorrência de trabalhos desses/ as estudantes na modalidade painel, que não é diferenciada nos anais do evento e, portanto, entra nesta contagem.

Fazendo uma observação na perspectiva longitudinal, os anos de 2010, 2013 e 2014 foram os que mais atraíram doutores/as, chegando a $74 \%$ em 2013 e $65 \%$ em 2014. Com o passar dos anos, contudo, discentes de doutorado e mestrado, assim como mestres, ganharam mais espaço, tendo superado em 2015, 2016 e 2017 o total de doutores/as apresentando trabalhos. Ou seja, abriu-se mais espaço para pesquisadores/as em formação, independentemente de sua posição na relação de autoria, pois aqui os dados estáo agregados, conforme se depreende da distribuiçáo apresentada no Gráfico 3.

Outro ponto interessante é entender a relação entre coautores/as. Por isso, apresentam-se os dados separados na Tabela 5. Como segundo/a autor/a, segue a predominância de doutores/as (54,8\%). Logo, poucos participantes da referida categoria tendem a escrever com seus/suas respectivos/as orientandos/as, por exemplo. No caso de terceira autoria também predominam doutores/as (40\%). Como se pode perceber, há discrepância entre doutores/as e as demais categorias, o que evidencia que, quando

\section{Gráfico 3}

\section{Distribuição da escolaridade de autores/as durante os oito anos}

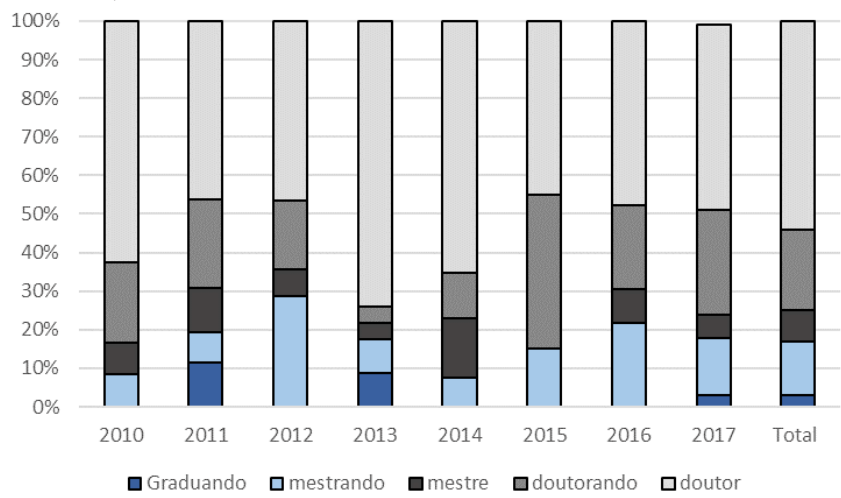

Fonte: Elaboraçẫo própria

Tabela 5

Distribuição da escolaridade entre autores/as e coautores/as

\begin{tabular}{ccccccc}
\hline Titulaçáa & $\mathbf{1}^{\mathbf{o}}$ autor/a & Percentual & $\mathbf{2}^{\mathbf{o}}$ autor/a & Percentual & $\mathbf{3}^{\mathbf{o}}$ autor/a & Percentual \\
\hline Graduando/a & 0 & 0 & 2 & 3,2 & 4 & 11,4 \\
\hline Mestrando/a & 15 & 14,2 & 9 & 14,5 & 5 & 14,3 \\
\hline Mestre/a & 7 & 6,6 & 7 & 11,3 & 2 & 5,7 \\
\hline Doutorando/a & 22 & 20,8 & 10 & 16,1 & 10 & 28,6 \\
\hline Doutor/a & 62 & 58,5 & 34 & 54,8 & 14 & 40,0 \\
\hline Total & 106 & 100,0 & 62 & 100 & 35 & 100,0 \\
\hline
\end{tabular}

Fonte: Elaboração própria 
há coautoria, esta tende a ocorrer com menor incidência entre indivíduos daquela primeira categoria e pesquisadores/as em formação.

Outro dado relevante para entender a composição do GT é em relação à área de atuação dos/as autores/as. Agregaram-se mais cientistas políticos $(24 \%)$ e sociais (31\%), no geral. $\mathrm{Na}$ área da comunicação, embora haja muitos estudos de ciberpolítica e cibercultura, a presença de pesquisadores/as da área teve menos espaço $(17,5 \%)$. Em quarto lugar apareceu a sociologia, com $10 \%$ das autorias. Destaca-se que há outras formaçōes (17,5\%), como em políticas públicas, direito, ciências da computação, informática, administração e economia, mas elas apareceram poucas vezes ao longo de todo o período e, por isso, foram agregadas na categoria "outros". Nenhuma delas, sozinha, se aproxima das quatro principais que têm caracterizado o GT.

Essa distribuição também foi observada ao longo do tempo para identificar como as diferentes áreas se inseriram ou se afastaram do GT. O Gráfico 4, que apresenta os dados longitudinais assim como o total, mostra que a ciência política tem reaparecido com mais ênfase nos últimos anos - havia perdido espaço entre 2011 e 2013. Autores/as advindos/as da comunicação, por outro lado, alcançaram mais espaço nos referidos anos e voltam a ganhar destaque em 2016 e 2017. A sociologia teve menos espaço no GT nos últimos anos, apesar da elevação de 2017. Enquanto isso, as ciências sociais mantiveram sua presença de modo mais estável ao longo do tempo, com um decréscimo mais significativo somente em 2011, notando-se até crescimento em 2017. Esses dados estáo diretamente relacionados aos/às autores/as que representam esse curso na PUC-SP e na UFABC.

Outro dado relevante trata das pesquisas interinstitucionais. Dentre os 63 papers escritos em parceria, mais da metade conta com autores/as da mesma instituição $(58,7 \%)$. Quanto ao total de textos, apenas $24,5 \%$ têm parceria

\section{Tabela 6}

\section{Parceria interinstitucional de autores/as}

\begin{tabular}{cccc}
\hline & Frequência & \% & \% Válido \\
\hline Não & 37 & 34,9 & 58,7 \\
\hline Sim & 26 & 24,5 & 41,3 \\
\hline Total & 63 & - & 100 \\
\hline Não se aplica & 43 & 40,6 & \\
\hline Total & 106 & 100 & \\
\hline
\end{tabular}

Fonte: Elaboração própria

Gráfico 4

Distribuição da formação de autores/as

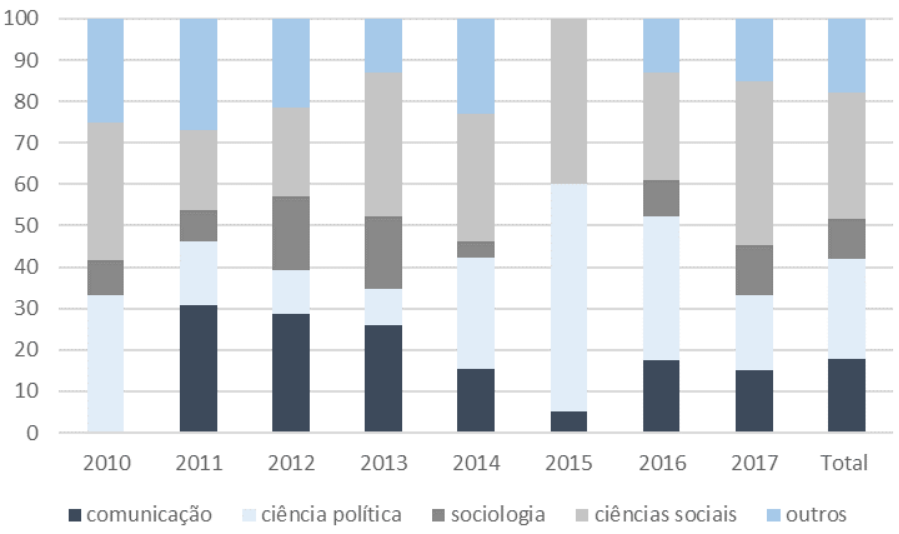

Fonte: Elaboração própria 
Tabela 7

Parceria entre autores/as de diferentes áreas de atuação

\begin{tabular}{cccc}
\hline & Frequência & $\%$ & \% válido \\
\hline Não & 41 & 38,7 & 65,1 \\
\hline Sim & 22 & 20,8 & 34,9 \\
\hline Total & 63 & 59,4 & 100,0 \\
\hline Não se aplica & 43 & 40, & \\
\hline Total & 106 & 100,0 & \\
\hline
\end{tabular}

Fonte: Elaboração própria

institucional. Esse dado aponta a baixa relação de pesquisas em rede, as quais demonstrariam parcerias efetivas entre os grupos de pesquisa.

Do mesmo modo, a parceria entre autores/as de áreas distintas - o que poderia trazer um ganho qualitativo aos trabalhos ao mesclar teoria e prática, discussões teóricas convergentes, entre outras possibilidades - também é algo raro. Isso ocorre em apenas $20,8 \%$ dos estudos. Logo, apesar de o GT agregar áreas distintas, elas aparentam ainda não conversar entre si nos artigos. Sendo assim, o GT acaba revelando a pouca relaçáo entre centros de pesquisa e a rara convergência entre as áreas, ainda que elas apareçam nas sessóes.

Passa-se, a seguir, à análise de conteúdo propriamente dita.

\section{Caracteristicas dos trabalhos}

A pesquisa também identificou como os trabalhos se distribuem nas áreas que compóem o GT, conforme o próprio título do grupo: Ciberpolítica, Cibercultura e Ciberativismo. Assim, 53,8\% deles são categorizados como ciberpolítica (57), enquanto ciberativismo abrange $28,3 \%$ dos papers (trinta) e cibercultura, 17,9\% (dezenove). Constata-se uma forte presença de estudos sobre internet e política, o que pode ser relacionado com a presença da ciência política como a segunda área mais presente no GT. Os dados longitudinais mostram algumas alteraçóes na presença das três subáreas do GT, principalmente o decréscimo de ciberpolítica, a consolidação do ciberativismo e a perda de espaço da cibercultura.

Nota-se que ciberpolítica estava representada na maior parte dos trabalhos nos três primeiros anos $(66,7 \%$ dos quinze totais, $50 \%$ dos quatorze e $68,8 \%$ dos dezesseis em 2010, 2011 e 2012, respectivamente). Depois desses anos, em 2015 e 2017, volta a aparecer em mais de $50 \%$ dos papers. Nos demais anos essa temática perde espaço para as outras áreas, principalmente para ciberativismo, que passa a se destacar no GT especialmente a partir de 2014, chegando a $38,5 \%$ dos artigos apresentados (cinco dos treze). Ademais, nota-se como o predomínio de ciberativismo acaba "sufocando" cibercultura, que é central em apenas um caso nos anos de 2015, 2016 e 2017.

Outra variável que demonstra como se consolidam e se constroem as pesquisas apresentadas no GT é a vertente de estudos, social (a respeito da apropriação das TICs por organizaçôes da sociedade civil) e institucional (relativa ao uso das TICs por instituiçôes governamentais), conforme a categorização de Sampaio, Bragatto e Nicolás (2016). Notase que predomina a vertente social $(59,4 \%)$ sobre a institucional (40,6\%). Isso chama atenção, pois os estudos de ciberpolítica, área predominante, estão mais relacionados às autorias advindas da ciência política, campo que possui notadamente um viés mais institucional em seus estudos. Quando se relacionam as áreas com as vertentes, todavia, nota-se que $68,4 \%$ dos trabalhos de ciberpolítica são da vertente institucional e apenas $31,6 \%$ da social, o que ainda é notável. Por outro lado, a grande incidência de uma vertente social está concentrada em ciberativismo - que 


\section{Gráfico 5}

\section{Distribuição temporal das áreas temáticas nos trabalhos do GT}

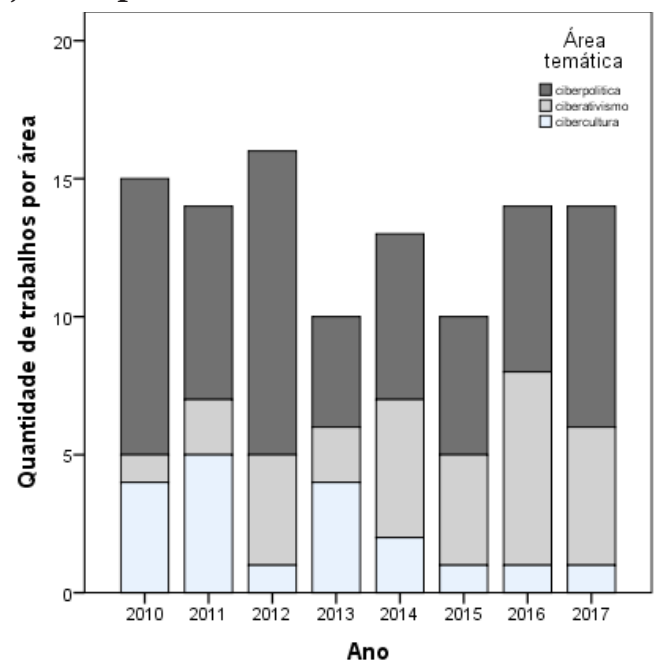

Fonte: Elaboração própria

Tabela 8

Distribuição das áreas temáticas do GT por vertente de estudos

\begin{tabular}{cccccc}
\hline & & Ciberpolítica & Ciberativismo & Cibercultura & Total \\
\hline \multirow{3}{*}{ Social } & $\mathrm{N}$ & 18 & 30 & 15 & 63 \\
\cline { 2 - 6 } & $\%$ & $31,6 \%$ & $100,0 \%$ & $78,9 \%$ & $59,4 \%$ \\
\cline { 2 - 6 } & $\mathrm{R} . \mathrm{p}$. & $-2,7$ & 2,9 & 1,1 & \\
\hline \multirow{3}{*}{ Institucional } & $\mathrm{N}$ & 39 & 0 & 4 & 43 \\
\cline { 2 - 6 } & $\%$ & $68,4 \%$ & $0,0 \%$ & $21,1 \%$ & $40,6 \%$ \\
\cline { 2 - 6 } & $\mathrm{R} . \mathrm{p}$. & 3,3 & $-3,5$ & $-1,3$ & \\
\hline \multirow{2}{*}{ Total } & $\mathrm{N}$ & 57 & 30 & 19 & 106 \\
& $\%$ & $100,00 \%$ & $100,00 \%$ & $100,00 \%$ & $100,00 \%$ \\
\hline
\end{tabular}

$\mathrm{x}^{2}=41.820 /$ Sig: 0,000

Fonte: Elaboraçăo própria

tem todos os trabalhos nessa categoria - e cibercultura, que apresenta essa categoria em quase $79 \%$ deles.

Aqui testou-se a existência de uma tendência de distribuição, o que gerou um coeficiente qui-quadrado significativo e tendência de ocorrência positiva significativa - ou seja, com resíduos padronizados (R.p.) fora do intervalo entre $-1,96$ e $+1,96-d a$ vertente social para a área de ciberativismo e negativa para ciberpolítica. O inverso, com quase os mesmos valores, ocorre em relação à vertente institucional. A temática cibercultura não apresentou resíduos padronizados significativos.

Ao observar a perspectiva longitudinal, chamou atenção o ano de 2011, em que há poucos trabalhos na vertente social. Em alguns anos a categoria institucional aparece mais, como 2010 e 2014. No entanto, há em geral 
um equilíbrio entre as duas categorias, com apenas essa tendência grande para a vertente social em 2011.

Pode-se, ainda, observar qual o objeto predominante nos trabalhos. Tem-se maior presença das categorias "instituiçôes” (27,4\%) e "movimentos sociais" (22,6\%), possivelmente na perspectiva de como usam as ferramentas tecnológicas. Apesar de parecer inconsistente o fato de os trabalhos terem mais vertente social e aqui predominarem as instituiçóes, vale observar a distribuição dos demais tipos de objeto, que podem reunir mais a perspectiva social que a institucional, como políticas de comunicação, esfera civil não organizada e sociabilidade, que agregam mais de 40\% das ocorrências.

Nota-se a baixa presença de trabalhos sobre campanhas eleitorais $(4,7 \%)$, que têm estudado a apropriação das ferramentas por candidatos, políticos e partidos no período da disputa eleitoral, que tendem a ser apresentados no GT de Mídia, Política e Eleiçóes. Há maior espaço para estudos sobre instituiçóes, mas fora do aspecto eleitoral.

Para entender melhor o que propriamente tem sido estudado pelos participantes do GT, há

Tabela 9

Distribuição dos objetos político/social

\begin{tabular}{lcc}
\hline & N & \% \\
\hline Instituições & 29 & 27,4 \\
\hline $\begin{array}{l}\text { Movimentos sociais e } \\
\text { organizaçôes cívicas }\end{array}$ & 24 & 22,6 \\
\hline Políticas de comunicaçáo & 21 & 19,8 \\
\hline Esfera civil não organizada & 17 & 16,0 \\
\hline Sociabilidade & 9 & 8,5 \\
\hline Campanhas eleitorais & 5 & 4,7 \\
\hline Outros & 1 & 0,9 \\
\hline Total & 106 & 100,0 \\
\hline
\end{tabular}

Fonte: Elaboração própria ainda o fator "objeto tecnológico" como variável central dos estudos do campo. Ressalta-se que os objetos "internet" e "mídia” são destinados às pesquisas mais gerais, com um objeto empírico ou pouco definido (normalmente mais presentes em reflexóes e ensaios sobre os meios de comunicação no geral) ou muito abrangente (no caso de estudar simultaneamente vários dos mecanismos apresentados), categorias que agrupam mais de $43 \%$ das pesquisas.

Por outro lado, nota-se a forte presença dos websites $(18,9 \%)$ e das mídias sociais $(26,4 \%)$ entre os principais objetos. Blogs, chats e softwares livres, por exemplo, não ganham tanto destaque no GT. O processo de desenvolvimento tecnológico leva à constante transformação dos objetos tecnológicos e à consequente transformação de seus estudos. Dessa forma, os trabalhos sobre blogs e chats vão perdendo espaço para estudos sobre mídias sociais nos últimos anos. Essa constante modificação de objeto mostra que a dinâmica da área está associada à relação entre tecnologia e sociedade.

Outra característica analisada é a abordagem teórica dos textos, podendo-se depreender uma abordagem bastante variada, sem nenhuma grande corrente dominando os estudos.

Tabela 10

Objetos tecnológicos de análise

\begin{tabular}{lcc}
\hline \multicolumn{1}{c}{ Objeto } & N & \% \\
\hline Internet & 43 & 40,6 \\
\hline Mídias sociais & 28 & 26,4 \\
\hline Websites & 20 & 18,9 \\
\hline Fóruns ou chats & 4 & 3,8 \\
\hline $\begin{array}{l}\text { Open source, software livre e } \\
\text { dados abertos }\end{array}$ & 4 & 3,8 \\
\hline Mídia & 3 & 2,8 \\
\hline Blogs & 3 & 2,8 \\
\hline Dispositivos móveis & 1 &, 9 \\
\hline Total & 106 & 100,0 \\
\hline
\end{tabular}

Fonte: Elaboração própria 
Apesar de abordagens variadas entre os trabalhos, percebem-se algumas menos frequentes, como jornalismo político (4,7\%). Isso se deve provavelmente à menor procura pelo GT por parte de autores/as que trazem essa reflexão, já que há outros espaços na Anpocs para discussóes mais centradas em mídia e política. Deliberação, apesar do grande destaque que recebe na literatura, também aparece menos no GT (4,7\%). Por outro lado, chama atenção a preocupação dos estudos com a economia política e as políticas de comunicação.

Tabela 11

Abordagem teórica

\begin{tabular}{lcc}
\hline \multicolumn{1}{c}{ Abordagem teórica } & N & $\%$ \\
\hline Identidade, sociabilidade e cidadania & 18 & 17,0 \\
\hline $\begin{array}{l}\text { Economia política/políticas } \\
\text { de comunicação }\end{array}$ & 17 & 16,0 \\
\hline Participação & 16 & 15,1 \\
\hline Engajamento & 14 & 13,2 \\
\hline Accountability e representação & 13 & 12,3 \\
\hline Estratégia política e eleitoral & 7 & 6,6 \\
\hline Deliberação & 5 & 4,7 \\
\hline Jornalismo político & 5 & 4,7 \\
\hline Transparência e informação & 4 & 3,8 \\
\hline Inclusão digital & 3 & 2,8 \\
\hline Outros & 3 & 2,8 \\
\hline Capital social e cultura política & 1 & 0,9 \\
\hline Total & 106 & 100,0 \\
\hline Eonte & & \\
\hline
\end{tabular}

Fonte: Elaboração própria
Um avanço importante que mostra a consolidação dos estudos do GT é a predominância dos trabalhos empíricos, 83\% do total, sendo somente $17 \%$ teóricos. No entanto, como o grupo tem três subáreas, é importante observar como essa constatação pode ser apropriada por cada uma delas.

A Tabela 12 mostra que dos 57 papers de ciberpolítica, apenas seis são teóricos, o que equivale a $10,5 \%$. Já no caso de ciberativismo, entre os 35 trabalhos, cinco possuem uma abordagem teórica, alcançando o percentual de $16 \%$. No caso de cibercultura, os sete artigos teóricos chegam a 36,8\% do total da subárea, que já tende a ser minoria no GT, conforme discutido anteriormente. Sendo assim, é a guinada da ciberpolítica e do ciberativismo que leva mais empiria ao GT.

Na sequência, observa-se o método de pesquisa utilizado nas pesquisas. Destaca-se a predominância de abordagem qualitativa $(46,2 \%)$ sobre a quantitativa $(23,6 \%)$, enquanto reflexões teóricas bibliográficas vêm em seguida (17\%). Outro ponto a se destacar é que 13,2\% dos trabalhos apresentados foram categorizados como método misto, por utilizarem as abordagens qualitativa e quantitativa.

De modo mais específico, observam-se as técnicas de pesquisa predominantes. Retirando os dezoito trabalhos que não são empíricos (16,3\%), $50 \%$ dos demais fazem análise de conteúdo. Nota-se que, apesar de a vertente qualitativa predominar no GT, há pouca apropriação de entrevistas, grupos focais e métodos de interação direta com o objeto de pesquisa, como etnografia.

Tabela 12

Tipo de estudo x Área temática do GT

\begin{tabular}{lccccc}
\hline & \multicolumn{3}{c}{ Área temática } & \multirow{2}{*}{ Total } \\
\cline { 2 - 5 } & & Ciberpolítica & Ciberativismo & Cibercultura & \\
\hline \multirow{2}{*}{ Tipo de estudo } & teórico & 6 & 5 & 7 & 18 \\
\cline { 2 - 5 } & empírico & 51 & 25 & 12 & 88 \\
\hline \multirow{2}{*}{ Total } & 57 & 30 & 19 & 106 \\
\hline
\end{tabular}

Fonte: Elaboração própria 
Tabela 13

Distribuição por tipo de método

\begin{tabular}{ccc}
\hline & N & \% \\
\hline Qualitativo & 49 & 46,2 \\
\hline Quantitativo & 25 & 23,6 \\
\hline Bibliográfico & 18 & 17,0 \\
\hline Quanti/quali & 14 & 13,2 \\
\hline Total & 106 & 100,0 \\
\hline
\end{tabular}

Fonte: Elaboração própria

Além da centralidade da análise de conteúdo em $50 \%$ dos trabalhos, percebe-se que nenhuma outra técnica se sobressai, havendo até poucos estudos que se utilizam de análise do discurso $(1,1 \%)$, por exemplo. Há papers que, apesar de se proporem à empiria, não apresentam um método específico de análise passível de se enquadrar entre os principais, o que chegou a 5,7\% deles. Por outro lado, percebe-se a entrada de novas técnicas, tal como a análise de redes, que obteve quatro ocorrências.

Outra característica observada é o uso da estatística, que aparece em cinquenta artigos $(47,2 \%)$, a partir de testes variados dentro do escopo do método, conforme se pode observar na Tabela 15.
Tabela 14

Técnicas de pesquisa utilizadas

\begin{tabular}{lccc}
\hline & N & \% & \% válido \\
\hline Análise de conteúdo & 53 & 50,0 & 60,2 \\
\hline Entrevista e grupo focal & 12 & 11,3 & 13,6 \\
\hline Análise documental & 6 & 5,7 & 6,8 \\
\hline Indefinido & 6 & 5,7 & 6,8 \\
\hline $\begin{array}{l}\text { Etnografia/observaçáo } \\
\text { participante e pesquisa- } \\
\text { açăo }\end{array}$ & 5 & 4,7 & 5,7 \\
\hline Análise de redes & 4 & 3,8 & 4,5 \\
\hline Survey & 1 &, 9 & 1,1 \\
\hline Análise do discurso & 1 &, 9 & 1,1 \\
\hline Total & 88 & 83,0 & 100,0 \\
\hline Năo se aplica & 18 & 17,0 & \\
\hline Total & 106 & 100,0 & \\
\hline
\end{tabular}

Fonte: Elaboração própria

Nota-se, entretanto, que não há avanços significativos com a utilizaçấo desse recurso analítico, pois prevalece de maneira expressiva o uso de frequências simples, o que aponta para um caráter mais descritivo dos trabalhos.

Tabela 15

Tipo de estatística utilizada

\begin{tabular}{lccc}
\hline & N & \% & \% válido \\
\hline Frequência simples & 41 & 38,7 & 82,0 \\
\hline Estatística univariada & 3 & 2,8 & 6,0 \\
\hline Estatística bivariada & 6 & 5,7 & 12,0 \\
\hline Total & 50 & 47,2 & 100,0 \\
\hline Não se aplica & 56 & 52,8 & \\
\hline Total & 106 & 100,0 & \\
\hline
\end{tabular}

Fonte: Elaboração própria 


\section{Considerações finais}

O estudo sobre a produção apresentada no GT Ciberpolítica, Ciberativismo e Cibercultura permitiu identificar algumas características da área, que, embora ainda em formação, começa a delinear suas especificidades. O objetivo da proposta foi mapear o perfil das pesquisas apresentadas durante os oito anos do GT, o que traz indicativos de como essa área multitemática tem se estruturado ao longo do tempo.

A análise permite afirmar que as pesquisas apresentadas no GT, com quase $50 \%$ de todos os trabalhos possuindo apenas um autor ou autora, possivelmente não são resultado de investigação coletiva ou de grupos de pesquisa, que normalmente contam com um processo colaborativo de produção. $\mathrm{O}$ trabalho de Sampaio, Bragatto e Nicolás (2016) segue os mesmos achados, o que demonstra que essa é uma prática comum na área, uma vez que a pesquisa mencionada trabalha com eventos de todo o campo de comunicação e política. Esse comportamento, todavia, é contrário àquilo que tende a ocorrer atualmente nas ciências humanas de modo generalizado, cujos trabalhos em coautoria nos últimos vinte anos saltaram de $2 \%$ para $40 \%$ em média, como indicam Codato et al. (2017).

Apesar da intrínseca característica interdisciplinar do grupo, com participantes de diversas áreas do conhecimento, por fazer parte de um congresso de ciências sociais a composição do GT tem uma maioria de participantes desse campo, notadamente da ciência política, indicando um viés mais próximo dos estudos sobre internet e política, como pode ser observado pela maior ocorrência de artigos de ciberpolítica. Esse perfil também pode estar associado à formação dos primeiros coordenadores do GT, oriundos da ciência política, seja pela formação ou pela área de produção atual.
Constata-se, ainda, que houve grande concentração de trabalhos apresentados em poucas instituiçóes, especialmente do eixo Sul-Sudeste. Isso pode indicar que o GT precisa estar mais atento à diversidade a ser contemplada quando da avaliação dos papers submetidos, uma vez que, há alguns anos, grupos de pesquisa que abordam essa interface têm se formado nas regióes Norte e Centro-Oeste, aquelas menos contempladas no GT, e ganhado alguma proeminência nacional. É surpreendente a redução de participação de instituiçóes do Nordeste nesse grupo, uma vez que no campo de internet e política a região é muito atuante (cf. SAMPAIO, BRAGATTO, NICOLÁS, 2016). Possivelmente isso seja explicado pelo fato de a maior parte de autores/as dessa região ser da área de comunicação e não das ciências sociais.

Não se pode deixar de perceber a menor participação e permanência de mulheres no GT. Esse fato segue em movimento contrário àquele de crescimento das mulheres no setor científico no Brasil, iniciado na década de 1980 (LETA, 2003) e intensificado especialmente nos últimos anos, quando as mulheres atingiram a marca de $49 \%$ da autoria de trabalhos acadêmicos no país (ELSEVIER, 2017).

Por fim, pode-se apontar que os estudos têm se caracterizado nos últimos anos como mais empíricos, preocupados em compreender fenômenos políticos, especialmente quanto à sua relação com os media digitais. Todavia, continuam em um nível mais descritivo de observação, o que indica uma tentativa de mapeamento dos casos a partir de uma análise de conteúdo de diferentes mecanismos com maior foco nas instituiçóes do Estado, especialmente o parlamento, e na sociedade civil organizada, achados que corroboram os resultados de Sampaio, Bragatto e Nicolás (2016).

Diferentemente de outras áreas da ciência política, contudo, o viés institucional não é a principal vertente nos estudos apresentados no GT, havendo certo equilíbrio com 
o viés social, que chega a apresentar maior ocorrência. Dessa forma, os estudos de caráter predominantemente empírico mostram uma pluralidade de objetos de pesquisa, com maior ênfase em instituições, movimentos sociais e políticas de comunicação. Percebe-se a diversidade de abordagens, como questóes de identidade, sociabilidade, cidadania, engajamento, economia política, accountability, entre outras.

Esses traços denotam a especificidade do campo de estudos sobre internet, caracterizado por permitir formas de mobilização/ ação institucionais e não institucionais que envolvem aspectos não só políticos, mas também sociais, culturais e tecnológicos. Assim como o desenvolvimento de novas tecnologias digitais (softwares, plataformas, mídias sociais etc.) e diferentes formas de apropriação e uso dessas tecnologias, o campo produz inovaçóes e desafios aos/às pesquisadores/as.

Esses resultados também permitem observar algumas lacunas que podem indicar novas agendas de pesquisa. Além do incentivo a uma maior pluralidade de autoras e instituiçóes presentes nas diferentes regióes do Brasil, o estudo ainda destaca a necessidade de maior cuidado metodológico. Por um lado, detecta-se uma reduzida gama de técnicas empregadas, concentradas em análise de conteúdo e, geralmente, apenas com estatística descritiva básica - algo aparentemente geral da área de internet e política, como apontado pelo estudo de Sampaio et al. (2016) enquanto é notável que os meios digitais, em sua constante e rápida evolução, estão constantemente demandando novas técnicas de averiguação e cuidados com questóes específicas a esses meios (e.g. robôs usados para divulgar candidatos e/ou ideias, páginas divulgando fake news, ou até os algoritmos que regem as mídias sociais).

Com a possibilidade da mineração e análise de altos volumes de informação (i.e., Big Data), as técnicas estatísticas e de análise de redes deveriam receber cada vez mais atenção e refinamento. Isso, por outro lado, não deve significar o abandono das técnicas de pesquisa tradicionais. Afinal, as pesquisas não podem se centrar exclusivamente no conteúdo das plataformas digitais, mas devem estar atentas a seus criadores, hospedeiros e usuários, o que reforça o uso de entrevistas, surveys, grupos focais e mesmo etnografias (com as devidas adaptaçóes aos meios em questão). É justamente nesse sentido que uma maior interdisciplinaridade e a ocorrência de mais coautorias parecem ser caminhos frutíferos para tais avanços.

Em especial é preciso reconhecer que a dinâmica informacional, o rápido desenvolvimento tecnológico e as diferentes formas de apropriação das TICs fazem com que a área esteja sempre se reconfigurando, surgindo novos objetos de estudo, novos problemas e novas ferramentas de pesquisa que visam explicar um fenômeno complexo e em constante transformação, sempre aberto para inovadoras formas de estudo nas ciências sociais.

Diante de tal desafio o que se pode concluir, enfim, é que, apesar de alguns ajustes ainda serem necessários, o GT estudado tem auxiliado no desenvolvimento de um campo interdisciplinar de estudos, apresentando avanços e se constituindo como um importante espaço para o fortalecimento das pesquisas.

\section{Referências}

ALBUQUERQUE, A. Notas para uma agenda da pesquisa sobre a propaganda política na televisão no Brasil. Eco-Pós, Rio de Janeiro, v. 12, n. 3, p. 4-10, 2010. 
AMARAL, A.; MONTARDO, S. P. Mapeamento temático da história da cibercultura no Brasil. In: CONGRESSO BRASILEIRO DE CIÊNCIAS DA COMUNICAÇÃO, 35., 2012, Fortaleza. Anais... São Paulo: Intercom, 2012. p. 1-17. v. 1.

ARAÚJO, R. P. A. et al. Democracia digital e experiências de e-participação: webativismo e políticas públicas. História, Ciências, Saúde-Manguinhos, Rio de Janeiro, v. 22, p. 1597-1619, dez. 2015.

CASTELLS, M. A era da informação: economia, sociedade e cultura. São Paulo: Paz e Terra, 1999.

. A galáxia internet: reflexôes sobre a internet, negócios e a sociedade. Rio de Janeiro: Zahar, 2003.

Redes de indignação e esperança: movimentos sociais na era da internet. Rio de Janeiro: Zahar, 2017.

CODATO, A. et al. A colaboração na ciência política brasileira: um estudo exploratório do padrão de coautorias em periódicos nacionais. In: CONGRESSO LATINOAMERICANO DE CIENCIA POLITICA, 9., 2017, Montevidéu. Anais... Montevidéu: Associación Latinoamericana de Ciencia Politica, 2017. p. 1-22.

COMITÊ GESTOR DA INTERNET NO BRASIL - CGI.BR. Pesquisa Sobre o Uso das Tecnologias de Informação e Comunicação no Brasil - TIC Domicílios 2017. Coord. Alexandre F. Barbosa. São Paulo: CGI. br, 2018.

DIAS, M. R. Nas brumas do HGPE: a imagem partidária nas campanhas presidenciais brasileiras (1989 a 2010). Opiniāo Pública, Campinas, v. 19, n. 1, p. 198-219, 2013.

ELSEVIER. Gender in the Global Research Landscape: analysis of research performance through a gender lens across 20 years, 12 geographies, and 27 subject areas. Amsterdam: Elsevier, 2017. Disponível em: <http://bit.do/egw7N>. Acesso em: 15 maio 2018.

FIGUEIREDO, M. et al. Estratégias de persuasão eleitoral: uma proposta metodológica para o estudo da propaganda eleitoral. Opinião Pública, Campinas, v. 4, n. 3, p. 182-203, 1997.

GOMES, W. Transformação da política na era da comunicação de massa. São Paulo: Paulus, 2004.

. 20 anos de política, estado e democracia digitais: uma cartografia do campo. In: SILVA, S. P.; BRAGATTO, R. C.; SAMPAIO, R. C. (Orgs.). Democracia digital, comunicação política e redes: teoria e prática. Rio de Janeiro: Letra \& Imagem, 2016. p. 25-45.

HARLOW, S.; HARP, D. Collective action on the Web: A cross-cultural study of social networking sites and online and offline activism in the United States and Latin America. Information, Communication \& Society, Abingdon, v. 15, n. 2, p. 196-216, 2012.

LEMOS, A. Cibercultura: tecnologia e vida social na cultura contemporânea. Porto Alegre: Sulina, 2002.

LEMOS, A.; LÉVY; P. O futuro da internet: em direção a uma ciberdemocracia planetária. São Paulo: Paulus, 2010. 
LETA, J. As mulheres na ciência brasileira: crescimento, contrastes e um perfil de sucesso. Estudos avançados, São Paulo, v. 17, n. 49 , p. $271-284,2003$.

LÉVY, P. Cibercultura. São Paulo: Editora 34, 1999.

LIMA, V. A. Revisitando sete teses sobre mídia e política no Brasil. Comunicação \& Sociedade, São Paulo, v. 30, n. 51, p. 13-33, 2009.

MIGUEL, L. F.; BIROLI, F. Comunicação e política: um campo de estudos e seus desdobramentos no Brasil. In: MIGUEL, L. F.; BIROLI, F. (Orgs.). Midia, representação e democracia. São Paulo: Hucitec, 2010. p. 7-24.

PANKE, L.; CERVI, E. Análise da comunicação eleitoral: uma proposta metodológica para os estudos do HGPE. Revista Contemporânea, Salvador, v. 9, n. 3, p. 390-404, 2011.

RUBIM, A. A. C.; AZEVEDO, F. A. Mídia e política no Brasil: textos e agenda de pesquisa. Lua Nova, São Paulo, 43, 189-216, 1998.

SAMPAIO, R. C.; BRAGATTO, R. C.; NICOLÁS, M. A. A construção do campo de internet e política: análise dos artigos brasileiros apresentados entre 2000 e 2014. Revista Brasileira de Ciência Política, Brasília, n. 21, p. 285-320, 2016.

SILVEIRA, S. A. Ciberativismo, cultura hacker e o individualismo colaborativo. Revista USP, São Paulo, n. 86, p. 28-39, 2010.

WEBER, M. H. O estatuto da Imagem Pública na disputa política. Eco-Pós, Rio de Janeiro, v. 12, n. 3, p. 79-94, 2009.

\section{Resumo}

Ciberpolitica, ciberativismo e cibercultura: uma análise dos papers apresentados no grupo de trabalho da Anpocs

Levando em conta a consolidação da atenção acadêmica aos fenômenos que envolvem a intersecção entre internet e política, este estudo busca compreender como ocorre tal produção científica no âmbito das ciências sociais no Brasil. Para isso, o artigo analisa os papers apresentados no grupo de trabalho Ciberpolítica, Ciberativismo e Cibercultura ( $\mathrm{N}=106)$, da Anpocs, desde a sua criação, em 2010, até 2017. Compreende-se que esse grupo representa uma amostra significativa do interesse acadêmico a respeito do assunto no contexto brasileiro. O estudo visa depreender o perfil dos/ das autores/as, das temáticas, das teorias e das pesquisas realizadas, buscando perceber se há mudanças nesses aspectos ao longo dos oito anos observados e identificar agendas de pesquisa. Os resultados indicam, dentre outros fatores: predomínio de textos de autoria única; equilíbrio de gênero quanto à autoria; predominância de artigos empíricos; e grande concentração de trabalhos em poucas instituiçốes de ensino superior.

Palavras-chave: Internet e Política; Ciberpolítica; Ciberativismo; Cibercultura; Democracia Digital.

\section{Abstract}

Cyberpolitics, cyberactivism, and cyberculture :an analysis of papers presented in the Anpocs workgroup

Considering the consolidation of academic attention to the phenomena involving the intersection between Internet and Politics, this study aims to understand this academic production in the area of Brazilian Social Science. To achieve 
this, this article analyzes the papers presented in the Workgroup Cyberpolitics, Cyberactivism, and Cyberculture $(\mathrm{N}=106)$ of ANPOCS, from its creation in 2010 to 2017 . We understand that this workgroup represents a significant sample of the academic interest regarding the subject in the Brazilian context. This study aims to identify the profile of the authors, themes, theories, and researches conducted, in addition to checking if there were changes in these aspects over the eight years observed and identifying research agendas. The results point out that: single-authorship texts predominate; there is a gender balance in the authorship; there is a predominance of empirical articles; and there is a great concentration of work in few higher education institutions.

Keywords: Internet and Politics; Cyberpolitics; Cyberactivism; Cyberculture; Digital Democracy.

\section{Résumé}

Cyberpolitiques, Cyberactivisme et Cyberculture : une analyse des articles presentés dans le groupe de travail Anpocs

Dans le contexte de consolidation de l'attention académique aux phénomènes à propos de l'intersection entre l'Internet et la politique, cet étude cherche la compréhension des dynamiques de production scientifique dans les Sciences Sociales au Brésil. Donc, l'article analyse les textes présentés au Groupe de Travail (GT) Cyberpolitique, Cyberactivisme et Cyberculture ( $\mathrm{N}=106)$ de l'ANPOCS, depuis sa création $(2010$ - 2017). On comprend que le GT représente un extrait significatif de l'intérêt académique à propos de ce sujet là dans le contexte brésilien. L'étude a l'intention d'identifier le profil des auteurs, des thèmes, des théories, et des recherches. En plus, on cherche s'il y a des changements dans ces caractéristiques au long des années observées et indiquer des agendas de recherche. Les résultats indiquent que : les textes d'un unique auteur sont prédominants; il y a un équilibre de genre entre les auteurs; les articles empiriques sont la majorité; et il y a une grande concentration de travails parmi peu d'institutions d'enseignement supérieures.

Mots-clés: Internet et politique ; Cyberpolitiques ; Cyberactivisme ; Cyberculture ; Démocratie Digitale. 